\title{
Intradural Extramedullary Plasmacytoma in a Dog
}

\author{
Vanessa Martins Fayad Milken', Lilian Hilario Cursino', Fernanda Gabriela Menegon², \\ Gustavo Gonçalves Parisi' ${ }^{2}$, Karina Michelle Braga ${ }^{3}$ \& Alessandra Aparecida Medeiros-Ronchi ${ }^{3}$
}

\begin{abstract}
Background: Plasmacytoma is a neoplasm originating in plasma cells, derived from B lymphocytes. Extramedullary presentation is the most common form of plasmacytoma, mainly in the skin and rarely in other tissues, including the vertebral canal. Extramedullary plasmacytoma (EMP) occurs more frequently in senile dogs and rarely in cats and some dog breeds have predisposition for this type of neoplasm. The aim of this study was to report plasmacytoma in a dog located adjacent to the thoracic vertebrae.

Case: An approximately 5-year-old mongrel male with sudden paraplegia resulting from upper motor neuron injury was admitted to a University Hospital. The dog presented a six-centimeter diameter mass in the dorsal region, adjacent to the thoracic vertebrae. The leucogram presented mild leukopenia by eosinopenia and lymphopenia. Myelogram associated with epidurography showed a fill failure in the contrast column between the seventh and ninth thoracic vertebrae, and there were no osteolysis points in the thoracic vertebrae, adjacent to the neoplastic mass. The evaluation of the intervertebral spaces between the fourth to ninth thoracic vertebrae presented no increase in radiopacity, nor alterations in the size of intervertebral spaces, indicating intervertebral disc extrusion. The laterolateral radiographs showed an alignment of the vertebrae and vertebral canal, without presence of bone neoformations on the ventral face of the vertebral bodies. The animal was euthanized and fragments of mass were collected for histological analysis. Macroscopic findings presented a non-encapsulated well-delimited mass, with color ranging from white to reddish. Microscopically, there was proliferation of moderately differentiated round cells in bone and muscle tissues, arranged in mantle, with moderately eosinophilic cytoplasm, and rounded nucleus with eccentric location, coarse chromatin sometimes indistinct. These cells presented moderate anisocytosis and, in general, one mitosis per field. Intradural extramedullary plasmacytoma was diagnosed.

Discussion: The present report presented a diagnosis of intradural EMP, generating compression of the spinal cord because of its invasive growth, reaching the canal and, thus, reducing its lumen. The clinical status of the dog was compatible with thoracolumbar lesion of upper motor neuron, which causes paresis and ataxia in pelvic limbs. In this case, it was not possible to establish early diagnosis because the dog had been rescued from the streets recently. Radiographic examination was important to identify the real size of the mass, and the myelography confirmed spinal cord compression. The definitive diagnosis was obtained by histological examination. Although extramedullary plasmacytoma is a low-frequency neoplasm, in the present report, its manifestation was atypical, more aggressive, invading the medullary canal and compressing the spinal cord. Spinal cord compression may lead to degeneration of axons because of alterations in the vascular permeability associated with local inflammatory process, reducing the oxygen supply to nervous tissues, resulting in cellular degeneration. The occurrence of atypical neoplastic growth should be included as a differential diagnosis for lesions in upper motor neuron in cases of spinal cord compression. This is an atypical location for this kind of neoplasia, and cases of medullary compression of neoplastic masses should be included as a differential diagnosis.
\end{abstract}

Keywords: myelography, lymphoid neoplasia, spine, canine, diagnosis. 


\section{INTRODUCTION}

Plasmacytoma is a low-frequency neoplasia in dogs and it originates from mature, differentiated B lymphocytes. The neoplastic cells resemble or are plasma cells, arising from excessive multiplication and at different stages of differentiation, affecting soft tissues [5].

According to the World Health Organization (WHO), hematopoietic and lymphoid neoplasms can be classified into extramedullary plasmacytoma (EMP), solitary plasmacytoma of bone (SPB), and multiple myeloma (MM) [16]. The WHO classification has been used in dogs [5].

The most common form of this neoplasm is EMP without bone marrow involvement. EMP occurs more frequently in senile dogs and rarely in cats $[4,5]$. Some dog breeds have predisposition for this type of neoplasm, such as Yorkshire Terrier, Airedale Terrier, Kerry Blue terrier, Scottish Terrier, Cocker Spaniels, and Poodles [5,15].

When EPM affects the skin, it is called cutaneous extramedullary plasmacytoma and is usually benign [5]. But it can occur in other areas, such as gastrointestinal tract, lungs, spleen, kidney, vertebral canal, and brain $[5,15]$. Extramedullary plasmacytoma may also progress to multiple myeloma or plasma leukemia [9].

EMP become more aggressive when invasion and destruction of adjacent tissues occur, with great chances of metastatic processes. Some surgical or chemotherapeutic therapies are adopted for this type of neoplasm, but its location is determinant for the therapeutic decision and prognosis.

The aim of this study was to report plasmacytoma in a dog located adjacent to the thoracic vertebrae, describing the clinical, radiographic, hematological and histopathological aspects.

\section{CASE}

An adult male mongrel dog was attended at the Veterinary Hospital of the Federal University of Uberlândia (HOVET-UFU), with a history of sudden paraplegia at approximately four days ago. At physical examination the dog presented a mass of six centimeters in diameter in the left antimere in the dorsal region, adjacent to the thoracic vertebrae. This mass had firm consistency and irregular shape and was adhered to the musculature. Blood was collected for hemogram and biochemical analysis.
The leucogram presented mild leukopenia by eosinopenia and lymphopenia (Table 1). Biochemical tests of creatinine (10.9 $\mathrm{mg} \mathrm{L}^{-1}$ [RI (reference interval) 5-17 mg L-1]), albumin (22.9 $\mathrm{g} \mathrm{L}^{-1}$ [RI 23-31 $\left.\left.\mathrm{g} \mathrm{L}^{-1}\right]\right)$, and alanine aminotransferase (26 IU L-1 [RI 10-109 IU L-1]) were performed and their levels were within the normal range for the species.

Simple radiographic images showed a circular radiopaque structure in regions of the fourth, fifth, and sixth left ribs, compatible with bony callus (Figure 1A), presenting the radiolucent line up to the sixth rib because of approximation of the edges of the fracture line. The later-lateral projection showed an increase in volume and radiopacity in soft tissues between the fourth and ninth thoracic vertebrae, compatible with the location of the tumor mass (Figure 1B).

Myelography was performed, with injection of an iodinated contrast (Omnipaque ${ }^{\circledR 1} 300 \mathrm{mg} / \mathrm{mL}$ ) at a dose of $0.3 \mathrm{mg} \mathrm{kg}^{-1}$ applied in cisterna magna, with previous sedation, trichotomy, and local asepsis. Immediately after the slow application of the contrast medium, serial radiographs were performed, with right and left laterolateral, and ventrodorsal projections to identify the site of the compromised spinal cord. The radiographic images showed an interruption in the progression of the contrast column in the region of the sixth thoracic vertebra. Thus, we choose epidurography as a complementary test, with application of iodinated contrast in the lumbosacral intervertebral space, at a dose of $0.2 \mathrm{mg} \mathrm{kg}^{-1}$, in which it was possible to delimit the affected region (Figure 2A).

The new serial sequence of radiographs confirmed the interruption of the contrast column in the region of the sixth to eighth thoracic vertebrae, with slight deviation to the right of the contrast column in the eighth thoracic vertebra, compatible with the intradural extramedullary compression pattern (Figure 2B).

Simple and contrast radiographs showed no osteolysis points in the thoracic vertebrae, adjacent to the neoplastic mass. The evaluation of the intervertebral spaces between the fourth to ninth thoracic vertebrae presented no increase in radiopacity, nor alterations in the size of intervertebral spaces, indicating intervertebral disc extrusion. The laterolateral radiographs showed an alignment of the vertebrae and vertebral canal, without presence of bone neoformations on the ventral face of the vertebral bodies. 


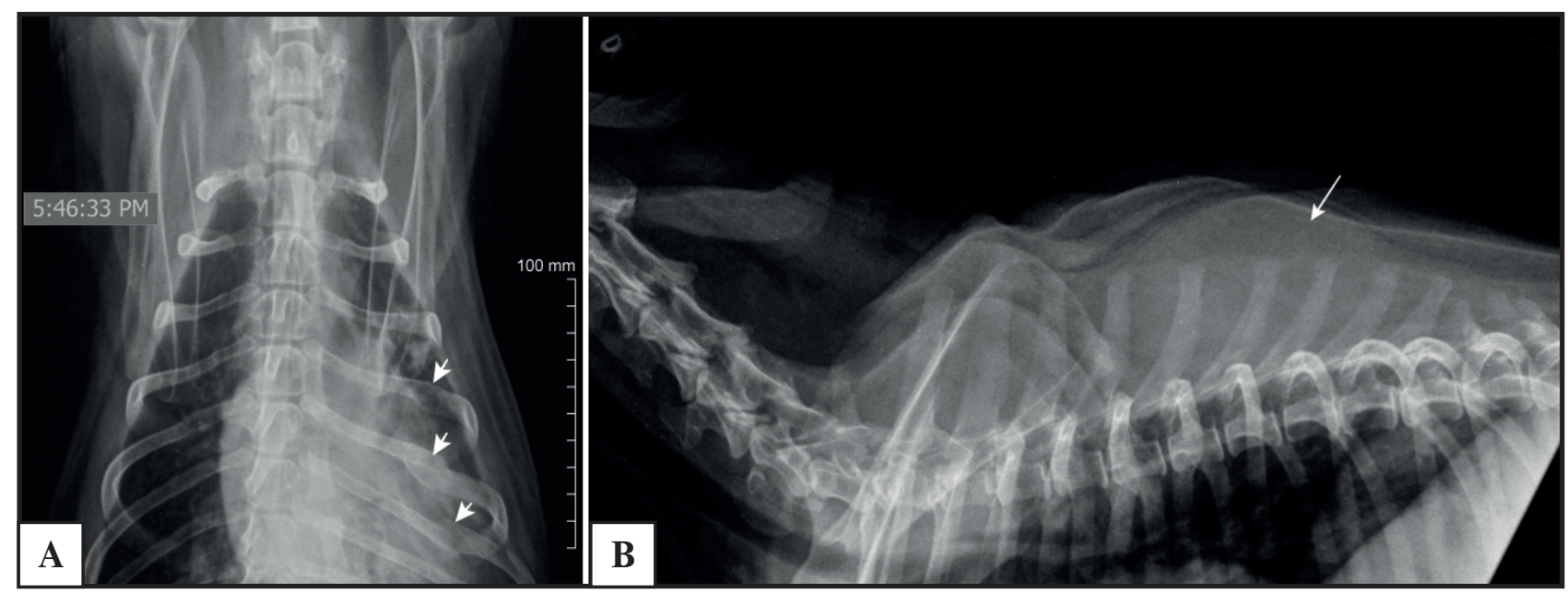

Figure 1. Dog, male, without defined breed, adult, with diagnosis of intradural-extramedullary plasmacytoma. A- Presence of rounded radiopaque structures (arrows) in the fourth, fifth and sixth left ribs region. B- Increase in volume and radiopacity (arrow) in soft tissues, in the region between the fourth and ninth thoracic vertebrae, consistent with the region of the mass.

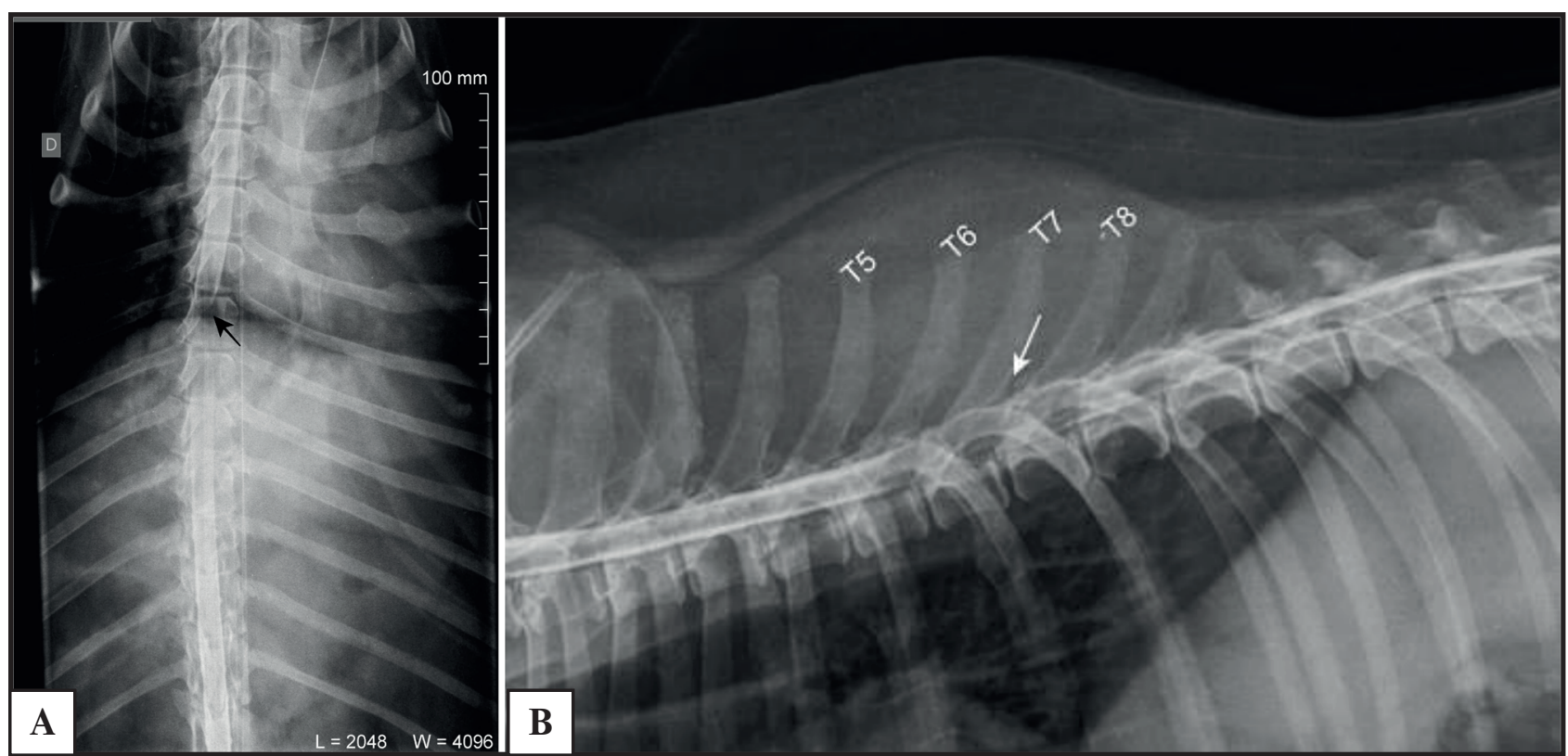

Figure 2. In the ventrodorsally (A) and later lateral (B) projections. Note the thinning of the contrast column with the direct deviation (black arrow) and the interruption of the contrast column between the sixth to the eighth thoracic vertebra, consistent with the site of the mass and with an intraduralextramedullary compression pattern.

The result of the cytological examination was inconclusive due to the contamination of the sample by a large amount of red blood cells and the scarcity of cells. The dog was euthanized due to the worsening of the clinical status of the animal and impossibility of surgical treatment and cure. At necropsy, a mass of approximately $6 \mathrm{~cm}$ in diameter, with an unctuous aspect, with alternating white-yellowish to rosy-reddish areas, invading the vertebral canal was identified, confirming the diagnosis of spinal cord compression with invasion of the neoplasm in the spinal canal (Figure 3).
Microscopically, the fragment of the mass that was adjacent to the ribs presented proliferation of moderately differentiated round cells, with scarce stroma, which infiltrated the bone and muscular tissue (Figure 4A, 4B). The neoplastic cells were round, arranged in mantle, with moderately eosinophilic cytoplasm, and rounded nucleus with eccentric location, coarse chromatin, and sometimes indistinct. These cells presented moderate anisocytosis and one mitotic figure per 10 high power fields (Figure 4C). The fragment presented extensive areas of necrosis and many vessels 


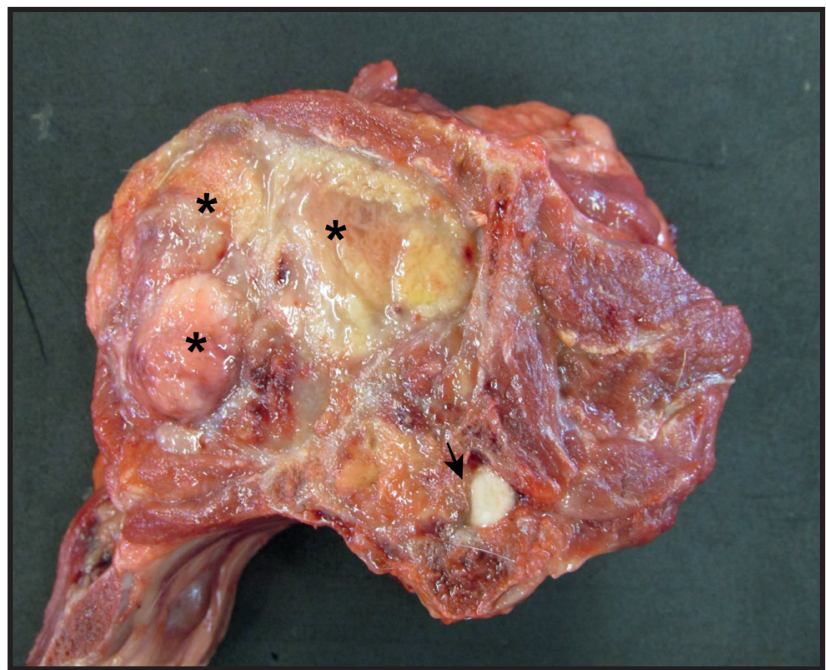

Figure 3. Neoplastic mass invading the medullary canal (arrow), causing spinal cord compression in the thoracic vertebra region (T7-T9). Neoplasia presented areas of the masses coloration (asterisks) alternating with areas of rosy coloration, of unctuous consistency.

filled with red blood cells (Figure 4D). Based on the clinical, radiografic and anatomopathological features the diagnosis was defined as nonmetastatic intradural extramedullary plasmacytoma.

\section{DISCUSSION}

The present report presented a diagnosis of intradural EMP, generating compression of the spinal cord because of its invasive growth, reaching the canal and, thus, reducing its lumen. Intradural EMP location is uncommon, presenting frequency of less than $1 \%$; and the most common site of its occurrence is the skin [15].

The clinical status of the dog was compatible with thoracolumbar lesion of upper motor neuron, which causes paresis and ataxia in pelvic limbs; when persisting the compression, this lesion becomes severe, with loss of pain and worsening of the neurological condition of the animal. In this case, it was not possible to establish early diagnosis because the dog had been rescued from the streets recently and, therefore, the tutor had not noticed neurological alterations due to the described thoracic mass. Moreover, early diagnosis is often difficult because of unapparent neurological initial damage $[11,14]$.

In some cases, the proliferation of tumor plasma cells may be associated with signs of hyperviscosity syndrome or paraneoplastic syndrome, such as hypercalcemia, thrombocytopenia, and other hematological abnormalities, and Bence Jones proteinuria, since their low molecular weights facilitate their passage through

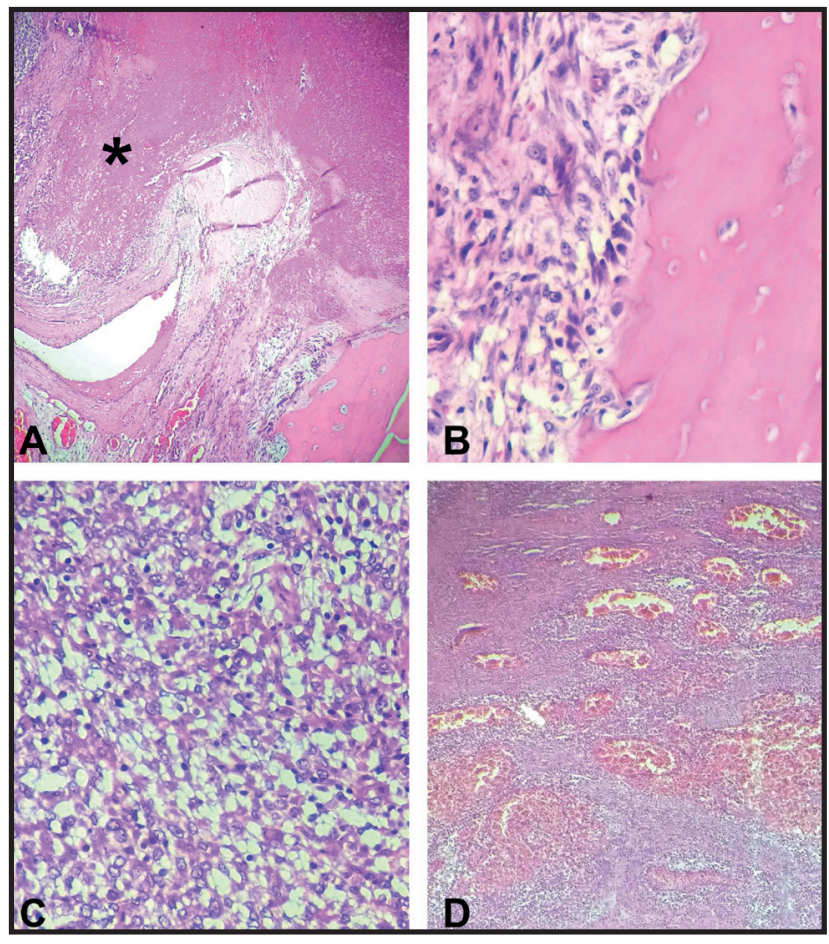

Figure 4. Plasmacytoma photomicrography. A- Neoplastic mass (*) adjacent to the thoracic vertebra [HE; 10x]. B- Infiltration of neoplastic cells into bone tissue [HE; 40x]. C- Proliferation of round cells with eccentric localization nucleus, moderately eosinophilic cytoplasm and coarse chromatin and sometimes indistinct nucleus [HE; 40x]. D- Areas with large amounts of vessels filled with red blood cells [HE; 10x].

the glomeruli, progressing to multiple myeloma $[5,10]$. Approximately $50 \%$ of extramedullary plasmacytoma cases in humans are diagnosed with hyperglobulinemia due to monoclonal gammopathy, and one in three cases evolve to multiple myeloma. Similarly, hyperglobulinemia in dogs is an indicative of aggressiveness [7]. The dog presented normal level of albumin and immunoglobulin dosage was not performed in the present case due to the rapid worsening of the dog's condition.

The hematological status of the dog presented few alterations; the discrete leukopenia by lymphopenia may be associated with a physical tension triggered by pain due to the compression of the spinal cord [12]. In addition, the discrete eosinopenia may be associated with the stress suffered at the time of the collection due to release of catecholamines by the neutralization of circulating histamines, and inhibition of eosinophil degranulation [19].

Radiographic examination was important to identify the real size of the mass, and the myelography confirmed spinal cord compression. Common findings in myelography were described in cases of plasmacytoma with intradural extramedullary compression $[2,3,18]$, reporting deviation of the contrast column 
with thinning by presence of mass in the subarachnoid space, and signs of medullary tumefaction. The area of medullary tumefaction is often associated with myelomalacia, but this association is inadequate [18].

The definitive diagnosis was obtained by histological examination. The histopathological findings were similar to those previously described as differentiated cells arranged in cords or nests, with high anisocorias, moderate anisocytosis, and elevated cell pleomorphism $[5,15]$. Although not observed in the present case, another finding in histological evaluations is the presence of Russell's corpuscle, which characterizes amyloid deposition due to lambda light chains of immunoglobulins and is one of the resources used to indicate the aggressiveness of the neoplasia [5,9]. Macroscopic findings presented a non-encapsulated well-delimited mass, with color ranging from white to reddish [5].

In the present case, the chances of success of the treatment were low, with an unfavorable prognosis due to the degree of impairment and severity of spinal cord compression. The location of the plasmacytoma is important to establish the prognosis. The excision of the tumor and the chemotherapeutic treatment have a good prognosis due to the low rate of recurrences of this type of neoplasm. In humans, its location at the base of the skull does not allow the adoption of surgical excision as a treatment measure and radiotherapy is used in this case [6].

Although extramedullary plasmacytoma is a low-frequency neoplasm, in the present report, its manifestation was atypical, more aggressive, invading the medullary canal and compressing the spinal cord. Spinal cord compression may lead to degeneration of axons because of alterations in the vascular permeability associated with local inflammatory process, reducing the oxygen supply to nervous tissues, resulting in cellular degeneration [1].

The occurrence of atypical neoplastic growth should be included as a differential diagnosis for lesions in upper motor neuron in cases of spinal cord compression.

\section{MANUFACTURER \\ ${ }^{1}$ Ge Healthcare. São Paulo, SP, Brazil.}

Funding. This study was partially funded by the Coordenação de Aperfeiçoamento de Pessoal de Nível Superior - Brasil (CAPES) - Finance Code 001.

Declaration of interest. The authors report no conflicts of interest. The authors alone are responsible for the content and writing of paper.

\section{REFERENCES}

1 Arias M.V.B., Severo M.S. \& Tudury E.A. 2007. Trauma medular em cães e gatos: revisão da fisiopatologia e do tratamento médico. Semina Ciências Agrárias. 28(1): 115-134.

2 Kealy J.K.K. \& McAllistter H. 2005. Diagnostic Radiology Ultrasonography of the Dog and Cat. St. Louis: Saunders Elsevier, 512p.

3 Mai W. 2014. Características das doenças da medula espinhal em cães e gatos pela ressonância magnética e por tomografia computadorizada. In: Thrall D.E. (Ed). Diagnóstico de Radiologia Veterinária. Rio de Janeiro: Elsevier, pp.194-221.

4 Majzoub M., Breuer W., Platz S.J., Linke R.P. \& Hermanns W. 2003. Histopathologic and immunophenotypic characterization of extramedullary plasmacytoma in nine cats. Veterinary Pathology. 40(3): 249-253.

5 Meuten D.J. 2017. Tumors in Domestic Animals. Tumors in Domestic Animals. Raleigh: Wiley-Blackwell, 989p.

6 Nofsinger Y.C., Mirza N., Rowan P.T., Lanza D. \& Weinstein G. 1997. Head and neck manifestations of plasma cell neoplasms. The Laryngoscope. 107(6): 741-746.

7 Pargass I., Bally A. \& Suepaul R. 2017. Oral plasmacytoma in a dog. Veterinary Sciences. 4(4): 68.

8 Rizzi T.E., Meinkoth J.H. \& Clinkenbeard K.D. 2010. Normal hematology of the dog. In: Weiss D.J. \& Wardrop K.J. (Eds). Schalm's Veterinary Hematology. Ames: Blackwell Publishing, pp.799-810.

9 Rout E.D., Shank A.M.M., Waite A.H.K., Siegel A., Avery A.C. \& Avery P.R. 2017. Progression of cutaneous plasmacytoma to plasma cell leukemia in a dog. Veterinary Clinical Pathology. 46(1): 77-84.

10 Rusbridge C., Wheeler S.J., Lamb C.R., Page R.L., Carmichael S., Brearley M.J. \& Bjornson A.P. 1999. Vertebral plasma cell tumors in 8 dogs. Journal of Veterinary Internal Medicine. 13(2): 126-133. 
11 Santos R.S., Fighera R.A., Beckmann D.V., Brum J.S., Ripplinger A., Neto D.P., Baumhardt R. \& Mazzanti A. 2012. Neoplasma envolvendo o sistema nervoso central de cães: 26 casos (2003-2011). Pesquisa Veterinária Brasileira. 32(2): 153-158.

12 Schultze A.E. 2010. Interpretation of Canine Leukocyte Responses. In: Weiss D.J. \& Wardrop K.J. (Eds). Schalm's Veterinary Hematology. Ames: Blackwell Publishing, pp.321-334.

13 Sharp N.J.H., Robertson I.D., De Carlo A., Smith G.K. \& Thrall D.E. 1995. Computed Tomography in the evaluation of caudal cervical spondylomyelopathy of the Doberman Pinscher. Veterinary Radiology and Ultrasound. 36(2): 100-108.

14 Taylor S.M. 2014. Neuromuscular disorders. In: Nelson R.W. \& Couto C.G. (Eds). Small Animal Internal Medicine. St Louis: Mosby Elsevier, pp.966-1102.

15 Vail D.M., Pinkerton M.E. \& Young K.M. 2013. Hematopoietic tumors. In: Withrow S.J. \& Vail D.M. (Eds). Withrow \& Mac Ewen's Small Animal Clinical Oncology. St. Louis: Saunders Elsevier, pp.608-679.

16 Vardiman J.W. 2010. The World Health Organization (WHO) classification of tumors of the hematopoietic and lymphoid tissues: An overview with emphasis on the myeloid neoplasms. Amsterdam: Chemico-Biological Interactions, pp.16-20.

17 Vezzali E., Parodi A.L., Marcato P.S. \& Bettini G. 2009. Histopathologic classification of 171 cases of canine and feline non-Hodgkin lymphoma according to the WHO. Veterinary and Comparative Oncology. 8(1): 38-49.

18 Widmer W.R. \& Thrall D.E. Vértebras do cão e gato. In: Thrall D.E. (Ed). Diagnóstico de Radiologia Veterinária. Rio de Janeiro: Elsevier, pp.172-193.

19 Young K.M. \& Meadows R.L. 2010. Eosinophils and their disorders. In: Weiss D.J. \& Wardrop K.J. (Eds). Schalm's Veterinary Hematology. Ames: Blackwell Publishing, pp.281-289. 